and vomiting some mothers were preoccupied and irritable and had to absent themselves. In addition, some resisted overeating by keeping limited amounts of food at home, and this complicated their child's feeding. The mothers' overconcern with shape and weight seemed also to have had an effect. It militated against breast feeding and was associated with undue concern about the children's shape and weight, which in turn affected how they were fed. Furthermore, the mothers' general psychiatric and personality disturbance may have influenced the children's development.'

This small case series suggests that further research is needed on the children of mothers with bulimia nervosa. If our findings are confirmed doctors and other health workers should be especially mindful of the feeding and development of such children.

We are grateful to the Wellcome Trust for its support and to Helen Woolley, Robert Peveler, and Pavlos Anastasiades for their help.

1 Rutter M. Parental mental disorder as a psychiatric risk factor. In: Hales RE, Frances AJ, eds. American Psychiatric Association annual review. Vol 6 . Frances AJ, eds. American Psychiatric Association a Washington: American Psychiatric Press, 1987:647-63.
King MB. Eating disorders in general practice. Br Med f 1986;293:1412-4 3 Fairburn CG, Cooper PJ. The clinical features of bulimia nervosa. Br $\mathcal{J}$ Psychiatry 1984;144:238-46.

Lacey JH, Smith G. Bulimia nervosa: the impact of pregnancy on mother and baby. Brf Psychiatry 1987;150:777-81.

(Accepted 26 fune 1989)

\section{Why are operations cancelled?}

\author{
Simon Morrissey, Thomas Alun-Jones, \\ Susanah Leighton
}

\author{
Department of \\ Otolaryngology, Radcliffe \\ Infirmary, Oxford \\ OX2 6HE \\ Simon Morrissey, FRCS, \\ registrar \\ Thomas Alun-Jones, FRCS, \\ lecturer \\ Susanah Leighton, $\mathrm{MB}$, \\ registrar
}

Correspondence to: Mr Alun-Jones.

Br.Med F 1989;299:778

\section{Patients, methods, and results}

A large proportion of otolaryngological operations are non-urgent. Many patients who are called for operation from waiting lists are not operated on. This results in inefficient use of beds and wastes operating time. Putting patients who will not receive an operation on waiting lists lengthens the waiting time for patients who will be operated on. We looked at the reasons why patients on our waiting list failed to have an operation.

In keeping with the recommendation of the Körner report' data on non-attendance of patients for operation are recorded monthly and reasons for non-attendance are sought by letter. We surveyed all patients who were called for operation from our waiting list from October 1987 to September 1988 but were not operated on.

During the study period 3654 patients were sent for and 2652 operations were performed. The table shows the 20 reasons for non-attendance in order of frequency of occurrence.

\section{Comment}

The rate of non-attendance of patients at an otolaryngology outpatient clinic has been reported ${ }^{2}$ but

Reasons why patients called for operation from otolaryngology department's waiting list failed to have operations during study

\begin{tabular}{lc}
\hline Reason & No of patients \\
\hline Upper respiratory tract infection & 219 \\
Operation not needed & 104 \\
Appointment inconvenient & 90 \\
Operation not wanted & 87 \\
Patient did not attend & 82 \\
Patient had moved away & 71 \\
Operation cancelled by hospital (no data) & 49 \\
Problems with job & 45 \\
Shortage of beds & 44 \\
Duplicate admission card (secretarial error & 30 \\
Other illness or operation & 30 \\
Operation done privately & 27 \\
Patients taking contraceptive pill & 22 \\
Shortage of anaesthetists & 22 \\
Shortage of nurses & 22 \\
Family illness & 20 \\
Poor medical work up & 14 \\
Patient hypertensive on admission & 10 \\
Ear infection & 7 \\
Postal difficulties & 7 \\
\hline Total & 1002
\end{tabular}

${ }^{\star}$ Reason unknown despite two reminders. the rate of non-attendance for operation has not. This is probably due to lack of information before the recommendations of the Körner report were implemented.' Our study showed that among patients called for operation from the waiting list the rate of non-attendance by patients was $14.6 \%$ and the rate of cancellation by the hospital was $12 \cdot 8 \%$.

We identified 20 reasons why patients did not have an operation. Upper respiratory tract infection, the most common reason, is independent of seasonal variation and beyond control. Most of the patients whose operation was found to be unnecessary on admission or who decided that they did not want an operation had been listed not by consultants but by junior doctors in busy clinics; probably the numbers could have been reduced by more active involvement of the consultants. This suggests that more consultants are needed in the health service and may indicate that a move to a consultant based service would be more efficient in the long term.

For 90 patients the date of admission was inconvenient. Two of the three consultants in the unit had given two weeks' notice of admission. The other consultant had booked admissions at outpatient consultations, giving three months' notice and a choice of date. The rate of non-attendance was similar for the three firms, suggesting that this reason for cancelling operations is beyond our control. The operations cancelled because the patients had hypertension or were taking oral contraception or because the medical work up had been inadequate were clearly under medical control. Shortages of staff caused 44 cancellations and a shortage of beds due to emergency admissions a further 44 cancellations.

We agree with a report of a House of Commons working party, which suggested that waiting lists could be reduced by computerisation, by confirming that patients would attend for operation, and by screening to prevent unnecessary admissions. ${ }^{3}$ None of these can be achieved without capital expenditure.

We did not find that absenteeism among consultants was a problem, but the numbers of patients to be seen by junior medical staff in outpatient clinics may result in inefficient management.

We thank Mr W S Lund, Mr B H Colman, and Mr A P Freeland for permission to use data on their patients, and Mrs C Hawley for secretarial help.

\footnotetext{
1 NHS/Department of Health and Social Security Steering Group on Health Services Information. First report. London: HMSO, 1982. (Korner report. Leese AM, Wilson JA, Murrav JAM. A survey of the non-attendance rate at the ENT clinic of a district general hospital. Clin Otolaryngol 1986;11:37-40 3 Committee of Public Accounts. Fiftieth report: use of operating theatres in the National Health Serice. London: HMSO, 1988

Accepted 3 fuly 1989
} 